\title{
The Role Of Earnings Quality In Financial Analyst Forecast Accuracy
}

\author{
David Salerno, University of Scranton, USA
}

\begin{abstract}
This study investigates the impact that the quality of reported earnings has on the accuracy of financial analysts' earnings forecasts. Extant research indicates that earnings attributes are important considerations to users of accounting information. One such attribute is earnings quality; often measured as the magnitude of accruals that do not convert to cash in a timely manner, where a poor match of cash flows and accruals indicates low earnings quality. Such accruals could reduce the usefulness of financial reports. This study uses two measurements of forecast accuracy to assess the impact that earnings quality has on the forecast accuracy of financial analysts. Following prior research, one measurement considers the environment in which the analyst operates and compares their accuracy to that of their peers. The second compares the individual analyst forecast to the actual reported earnings. For both measurements of accuracy the results show that higher earnings quality is associated with improved forecast accuracy.
\end{abstract}

Keywords: Analysts; Earnings Forecasts; Forecast Accuracy; Earnings Quality

\section{INTRODUCTION}

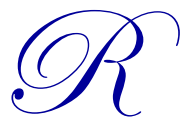

esearch shows the important role that the quality of accounting information plays in reducing asymmetries between firms and investors (Garcia-Teruel et al., 2009). Among other resources, analysts are known to rely on accounting information to develop earnings forecasts (Barker and Imam, 2008). Existing literature identifies several attributes of reported income that are widely considered to be desirable characteristics of a firm's reported earnings (Barton et al., 2010; Francis et al., 2004). One such attribute is earnings quality which is the aggregate result of the application of various accounting treatments, estimates, and assumptions that are made by management. Literature also finds that earnings quality is negatively associated with information asymmetry (Bhattacharya et al., 2003; Francis et al., 2004), and such an asymmetry could be expected to have an impact on the ability of analysts to predict earnings. By reducing these asymmetries higher quality earnings also leads to lower costs of capital and debt (Bhattacharya et al., 2003; Francis et al., 2004). Therefore because the quality of reported earnings is important to market participants it is useful to investigate its impact on financial analysts.

This study uses two measurements of forecast accuracy described in the literature to examine the effect that the quality of reported earnings has on the performance of individual financial analysts. The first considers the environment in which the analyst operates and compares their accuracy to that of their peers (Jacob et al., 1999). The second measurement compares the individual analysts' forecast to actual report earnings (Bae et al., 2008). Because reported financial accounting information is intended for users outside of the company, and because earnings is a "premier source" of such information (Francis et al., 2004), it is reasonable to assume that the quality of earnings could affect the decisions and outcomes of financial statement users. In fact Lobo et al. (2012) find that the services of financial analysts become more valuable to investors and in greater demand as earnings quality diminishes. However, it is also true that managers have incentives to manipulate earnings (Bauman \& Shaw, 2006; Brown, 2001; Graham et al., 2005; Matsumoto, 2002); a practice that could lead to lower quality earnings which are sometimes characterized as the result of management's opportunistic use of accruals with the intent to mislead users (Dechow \& Dichev, 2002), hereafter DD02. There have been several prior examinations of the relationship between various earnings attributes and financial analyst forecasts (Lobo et al., 2012; Bryan \& Tiras, 
2007; Eames \& Glover, 2003; Helbok \& Walker, 2004; Mensah et al., 2004), however the relationship between earnings quality and analyst forecast accuracy is largely unexamined. ${ }^{1}$

The literature contains several approaches to measuring earnings quality. One such approach is to measure how closely cash flows track with changes in working capital (DD02). In their model, any changes in working capital that cannot be explained by cash flows are considered to be the result of lower quality accruals. Because earnings quality informs investors about the mapping of accounting earnings into cash flows, poor quality earnings reports will increase information risk by weakening that connection (Francis et al., 2005). Furthermore, research finds that earnings measurements are more value relevant when they directly and quickly capture information about firms' cash flows (Barton et al., 2010). Using the DD02 method, this study examines the association between earnings quality and financial analysts' earnings forecast accuracy. The test results indicate that higher quality earnings enhance the accuracy of analysts' earnings forecasts. The results of this study will be useful to market participants by providing investors with further understanding of how accounting reports are processed by financial statement users; particularly by financial analysts.

The remainder of this paper is organized as follows. Part II provides a review of relevant prior literature and describes the hypothesis development. Part III describes the research method, variable descriptions, and data sample. Part IV provides the test results, and Part V includes a summary and conclusion.

\section{LITERATURE REVIEW AND HYPOTHESIS DEVELOPMENT}

\section{Literature Review}

Forecast accuracy literature finds that differences in financial analysts' earnings forecasts are mostly attributable to analyst, firm, industry, and country level attributes. Following is a review of the relevant forecast literature that provides these alternative explanations of the variability in analyst performance.

\section{Analyst Attributes}

Several studies find that forecast accuracy is a function of analyst innate ability, firm-specific experience (Clement, 1999), general experience (Mikhail et al., 1997), forecast horizon, individual experience, and prior accuracy (Clement, 1999; Jacob et al., 1999; Mikhail et al., 1997; Raedy et al., 2006). ${ }^{2}$ Burgstahler and Eames (2003) find that although firms engage in earnings management (Burgstahler \& Dichev, 1997; Guttman et al., 2006; Hayn, 1995; Jacob \& Jorgensen, 2007; Kerstein \& Rai, 2007; Roychowdhury, 2006), analysts are unable to sufficiently predict such manipulation. This could result in lower accuracy because the analyst's expectation of earnings management often causes them to reduce their estimates beyond actual earnings. In other accuracy literature, Kim and Parther-Kinsey (2010) test whether analysts' earnings forecast errors are a function of analysts' use of a proportionate cost model (PCM) in which the growth rate for both expenses and sales are assumed to be equal. Their study finds that such an assumption leads to forecast errors when expenses change at a different rate than sales.

Firm, Industry, and Country Level Attributes

Several approaches exist in prior literature to study firm level attributes. For instance, Dowdell (2010) investigates whether analyst accuracy is a function of a firm's life-cycle. That study finds that analysts have more

\footnotetext{
${ }^{1}$ Eames and Glover (2003) study the relationship between analyst earnings forecast errors and earnings predictability. They document associations between the level of earnings and both forecast errors and earnings predictability and find that optimism is not deliberate on the part of analysts. Helbok and Walker (2004) study the effect of conservatism on analyst performance and find that conservative accounting causes analysts to initially issue forecasts that are focused on permanent earnings. Mensah et al. (2004) find that conservatism is associated with higher forecast errors and dispersion. Bryan and Tiras (2007) also use forecast dispersion as a measurement of information asymmetry and find that when information asymmetry is high, analysts rely less on accounting information.

${ }^{2}$ Jacob et al. (1999) define innate ability as a "dispositional" analyst attribute that indicates high aptitude. They find analyst firm-specific experience to be insignificant in explaining analyst performance after controlling for innate ability, yet find, at the brokerage level, that analyst work place characteristics are a significant factor. They also suggest that those analysts that survive longest at a firm necessarily have natural (innate) talent, and that it is that talent, not firm nor task specific experience, that explains their performance.
} 
difficulty when forecasting earnings for mature firms than they do for growth firms. Additionally their results indicate that turnaround firms are the most difficult for which to predict earnings. ${ }^{3}$ International studies such as Ashbaugh and Pincus (2001) investigate whether the variation in accounting standards across national boundaries relative to IFRS has an impact on the ability of financial analysts to accurately forecast non-U.S. firms' earnings. They find that the convergence in firms' accounting policies resulting from the adoption of IFRS reduces analyst forecast errors. Uncertainty about financial and accounting information under internationally diverse accounting regimes is also shown to lead to less accurate forecasts (Ashbaugh \& Pincus, 2001; Bae et al., 2008, Tan et al., 2011). The effect of regulation on analyst performance also occupies an important segment of existing literature. Libby et al. (2008) finds that an optimistic/pessimistic pattern exists early and late in the firm quarter. They find that this pattern is due to relationships with management which have not completely disappeared with recent regulation. Mohanram and Sunder (2006) study the methods by which financial analysts attempt to retain their accuracy in the post-Regulation FD environment. ${ }^{4}$ They find that analysts are making a greater effort to develop information by reducing their following of well-followed firms and increase efforts for those that were less covered prior to the regulation. The results suggest that larger brokerages lost their advantage in the post-Regulation FD period due to the fairer distribution of information required buy Regulation FD. ${ }^{5}$ La Porta et al. (1998) show that common law countries provide superior minority shareholder protection compared to those with civil law systems. Building on those results, Barniv et al., (2005) test the ability of analyst characteristics to explain relative forecast error across legal origins (common law versus civil law). Their results suggest that analysts with superior characteristics will outperform those analysts in common-law countries because of the lowered incentives that exist when investor protections are low; thus establishing a link between legal and financial reporting environments and analysts' forecast behavior.

\section{Hypotheses Development}

Existing literature provides several reasons to expect earnings quality to have an effect on the accuracy of financial analysts' earnings forecasts. Prior studies show that reported earnings are a principal source of firmspecific information to interested parties (Francis et al., 2004), that managers themselves view earnings as the key metric evaluated by investors and analysts (Graham et al., 2006), and that investors rely on earnings more than any other summary measure of firm performance including dividends, cash flows, or variants of earnings such as EBITDA (Francis et al., 2004). The user uncertainty that could be caused by low quality earnings may reduce analyst performance. For example, such uncertainty about a firm's economic future increases dispersion patterns of analyst forecasts (Barron \& Stuerke, 1998; Imhoff and Lobo, 1992; Payne \& Robb, 2000). Existing research also documents an association between analyst performance and other earnings attributes. Helbok and Walker (2004) and Mensah et al. (2004) show that increased accounting conservatism is associated with greater forecast errors. ${ }^{6}$ Mensah (2004) also indicates that greater forecast errors and wider forecast dispersion result from decreases in earnings predictability. In another example of the value that market participants place on the quality of reported earnings, Francis et al. (2004) find that firms with the least favorable values for each of several earnings attributes that they examine (including earnings quality) have higher costs of equity than do firms with the most favorable values. There is also substantial support in the literature for the notion that higher earnings quality has a positive effect on stock price. Boulton et al. (2011) examine the impact of country-level earnings quality on IPO prices and find that IPOs are underpriced less in countries where public firms produce higher quality earnings information, thus highlighting the favorable effect that high earnings quality has on price. Additionally, Feng et al. (2011) find that financial reporting quality positively affects investment efficiency. Research also describes further motivation on the part of managers to produce higher quality earnings reports. Gaio and Raposo (2011) find a positive relationship between firm valuation and earnings quality, particularly for 1) firms with greater investment opportunities and

\footnotetext{
${ }^{3}$ Turnaround firms are defined by Dowdell (2010) as those firms that either 1) are expected to have negative abnormal future earnings but less negative as time goes on, or 2) have temporarily low earnings.

${ }^{4}$ Regulation Fair Disclosure ("Reg FD") requires firms to disseminate material information to all investors at the same time. The Securities and Exchange Commission stated that the objective of FD is to eliminate the practice of selective disclosure to preferred analysts. Regulation FD went into effect on October 23, 2000.

${ }^{5}$ See Barniv et al. (2009) for a discussion of the effects of regulation FD and subsequent regulations on analysts' stock recommendations and on stock returns.

${ }^{6}$ Their measure of conservatism is described as an accounting-based aggregate measure developed by Penman and Xiao-Jun (2002). It is defined as the unrecorded net assets resulting from using LIFO inventory method and expensing R\&D and advertising expenditures.
} 
having more need for external finance, and 2) for firms in low investor protection countries. ${ }^{7}$ Their results strongly suggest that higher quality reports are valued to a greater degree by the financial markets and that investors require a premium for the information risk associated with lower-quality earnings. In fact Agnes Cheng et al. (2012) find a positive association between abnormal accruals and mispricing of securities, pointing to the need for reliable earnings reports. ${ }^{8}$

The literature above provides the expectation that higher earnings quality (by providing analysts with more useful information) would enable analysts to produce more accurate forecasts. However the earnings management literature provides for the possibility that lower quality earnings may be associated with accurate forecasts. The results of these studies (Burgstahler \& Dichev, 1997; Burgstahler \& Eames, 2003; Jacob \& Jorgensen, 2007; Kerstein \& Rai, 2007; Roychowdhury, 2006) suggest that managers' reliance on low quality earnings to meet analyst forecasts might result in less differences between forecasts and reported earnings. Put another way, as the firm manipulates accounting information to adjust reported earnings closer to the forecast, earnings quality would decrease. Consequently the difference between the forecast and actual reported earnings decreases, making the forecasts appear to be accurate. Although this scenario seems less likely, it is considered in the hypotheses described below.

\section{Hypotheses}

It is reasonable to assume from the literature discussed above that the quality of reported earnings will affect financial analyst forecast accuracy, however the direction of that effect remains unclear in the literature. Therefore the hypotheses are stated in the null form. To investigate the impact of earnings quality on financial analyst forecast accuracy two hypotheses are tested.

The first hypothesis considers whether earnings quality has an impact on individual analyst forecast accuracy relative to other analysts. Literature shows that each individual analyst is positioned differently and performs (relative to other analysts) based on, among other things, the legal and financial reporting environment in which they operate (Barniv et al., 2005), their individual work place environment (Jacob et al., 1999), and their innate ability and task-specific experience (Clement et al., 2007). Because individual analysts bring unique sets of background and expertise to the forecasting task, it is anticipated that earnings quality accounts for some of the differences in accuracy among individual analysts. To investigate the influence of earnings quality on the accuracy of the individual the analyst's forecast compared to all other analysts' forecasts for the same firm and year, the following hypothesis, stated in the null form, is tested.

H1: The quality of reported earnings is not associated with individual financial analyst forecast accuracy relative to their peers.

The second hypothesis considers whether the quality of reported earnings affects analysts' forecasts relative to the actual reported earnings of the firm. To investigate this influence the following hypothesis, stated in the null form, is tested.

H2: The quality of reported earnings is not associated with financial analyst forecast accuracy relative to reported earnings.

\section{RESEARCH METHOD}

\section{Dependent Variables}

The effect of earnings quality on analysts' forecast accuracy is tested using two specifications of accuracy. The first is a measurement of relative forecast errors (RFE). This analyst-specific forecast error used in the accuracy specification uses the absolute difference between the EPS forecast and the actual EPS for the specific firm and year.

\footnotetext{
7 The Gaio and Raposo (2011) study uses an aggregate earnings quality measure based on earnings quality, persistence, predictability, smoothness, value relevance, timeliness, and conservatism.

${ }^{8}$ Their main test of mispricing relates current accruals to future returns.
} 


\section{Relative Forecast Error}

To construct the RFE variable, the first step is to calculate the absolute forecast error (AFE) as follows.

$$
\text { Absolute Forecast Error }=\mid \text { Forecast EPS }_{i t j}-\text { Actual EPS }_{i t j} \mid
$$

where Forecast EPS is the individual analyst i's most recent earnings per share forecast in the twelve months prior to the earnings announcement for firm $j$ and time $t$, Actual EPS is the reported earnings per share of firm $j$ for time $t, i$ is the individual analyst, $\mathrm{j}$ represents the firm, and $\mathrm{t}$ is the fiscal year of the firm's earnings announcement date.

The next step is to construct the mean absolute forecast error (MAFE). Following prior literature (Barniv et al., 2005; Jacob et al., 1999), accuracy is measured by using the relative forecast error (RFE) and is defined as the absolute forecast error above (AFE) divided by the mean absolute forecast error (MAFE) of all analysts' consensus forecast measured as follows:

Mean Absolute Forecast Error $=$ MAFE $=\mid \overline{\text { Forecast EPS }_{i t}-\text { Actual EPS }_{i t}}$

Finally, RFE is calculated by dividing AFE by MAFE and subtracting 1 from the ratio. Jacob et al. (1999) point out that by subtracting 1 from the ratio, forecasts of average accuracy will result in an RFE value of zero. To aid interpretation, the resulting values are multiplied by -1 so that the most accurate forecasts take on a value of 1 , forecasts of average accuracy remain zero, and lower than average accuracy will be negative:

$R F E=\left(A F E_{i t j} / M A F E_{t j}\right)-1$

\section{Absolute Forecast Error}

To further investigate the impact of earnings quality on analyst forecast accuracy; additional tests are performed following Bae et al. (2008) and Tan et al. (2011). The second dependent variable used (AFEP) is the absolute forecast error scaled by the prior year's price. It is a measurement of the accuracy of the earnings forecast issued by analyst $\mathrm{i}$ for firm $\mathrm{j}$ for year $\mathrm{t}$.

$$
A F E P_{i j t}=\frac{\left|F_{i j t}-A_{j t}\right|}{P R I C E_{j, t-1}}(-100)
$$

AFEP is computed as the absolute value of the forecast error scaled by the most recent stock price in the previous year and then multiplied by -100 to allow for a more intuitive interpretation; as accuracy increases, AFEP increases.

\section{Earnings Quality Variables}

The DD02 specification of earnings quality measures whether current accruals are associated with prior, current, or next period cash flows. Any accruals not associated with those cash flows are thought to reduce the quality of earnings. This method is used in prior work to explore the link between earnings attributes and cost of equity (Francis et al., 2004). Any deterioration in reliability of earnings could frustrate users regardless of whether the loss of reliability is due to intentional or unintentional errors. DD02 point out that unlike other extant measurements that assume earnings quality to be the result of intentional manipulation by management, this approach is indifferent to whether errors are intentional or not. Such an approach is consistent with the purpose of this study. By capturing the net effect of accounting application on the timing of accrual maturity, the model 
provides the aggregate effect of accounting policies and choices which is more relevant to assessing analysts' response. Therefore this study uses the unmodified DD02 specification to measure earnings quality. ${ }^{9}$

The dependent variable in the model is the change in working capital $(\triangle \mathrm{WC})$ and is computed as $\triangle \mathrm{AR}+$ $\Delta$ Inventory - $\triangle \mathrm{AP}-\Delta \mathrm{TP}+\Delta \mathrm{Other}$ Assets-net, where AR is accounts receivable, AP is accounts payable, and TP is taxes payable. Using Compustat nomenclature, $\triangle \mathrm{WC}$ is calculated specifically as Compustat item RECCH (Accounts Receivable, Decrease or Increase) + INVCH (Inventory, Decrease or Increase) + APALCH (Accounts Payable and Accrued Liabilities, Increase or Decrease) + TXACH (Income Taxes Accrued, Increase or Decrease) + AOLOCH (Other Assets and Liabilities, Net Change). All variables are scaled by average assets:

$\Delta \mathrm{WC}_{\mathrm{jt}}=\alpha+\beta_{1} \mathrm{CFO}_{\mathrm{j}, \mathrm{t}-1}+\beta_{2} \mathrm{CFO}_{\mathrm{jt}}+\beta_{3} \mathrm{CFO}_{\mathrm{jt}+1}+\mathrm{v}_{\mathrm{jt}}$

where $\triangle \mathrm{WCjt}$ is the change in working capital for firm $\mathrm{j}$ from year $\mathrm{t}-1$ to year $\mathrm{t}, \mathrm{CFO}_{\mathrm{jt}}$ is firm $\mathrm{j}$ 's cash flow from operations for firm $\mathrm{j}$ in year $\mathrm{t}$, and $\mathrm{v}_{\mathrm{jt}}$ represents the residuals for firm $\mathrm{j}$, year $\mathrm{t}$.

The residuals resulting from the estimation of the model represent changes in working capital from accruals that have not converted to cash flows in the three year window $(t-1, t$, or $t+1)$. According to DD02 earnings quality could be estimated from the model in two different ways; 1) the standard deviation of residuals of a time series of estimates could be used as a proxy for earnings quality (DDSD), and 2) the absolute value of the residual in the current year estimation (DDCR). ${ }^{10}$

It is reasonable to expect different results between the two variables. DDCR represents the level of earnings quality in a single year while DDSD measures the historical pattern of the distribution of the levels over five years prior to the earnings announcement. Because analysts are show in the literature to be more accurate over shorter horizons (Barniv et al., 2005; Clement, 1999, Jacob et al., 1999), in a longer horizon an analyst may draw information from the more historical measurement (DDSD). On the other hand, under shorter horizons the single year measurement (DDCR) could be more useful. When using the standard deviation method, the model is typically estimated using a rolling time series of estimations providing firm and year specific estimated residuals. The earnings quality measurement is then given as the standard deviation of the residuals per firm-year. A large standard deviation would indicate that a large portion of the variability in the change in working capital is not explained by one period lagged $\left(\beta_{1}\right)$, current $\left(\beta_{2}\right)$, or one period forward $\left(\beta_{3}\right)$ cash flow. The procedure results in an earnings quality measurement over years and represents historic smoothness (or volatility) in earnings quality for the firm over that period. This study uses both DDSD and DDCR as the earnings quality variable. For each method, pooled cross-sectional regressions are estimated providing an earnings quality variable for each reported earnings value in the sample. Finally, because earnings quality information must be available to analysts for it to have an impact on their performance, DDSD and DDCR are lagged by one year.

\section{Control Variables}

Prior literature provides guidance on controls that are relevant to analyst accuracy. For example, forecast accuracy is positively associated with the size of the analysts' employer, but negatively associated with both the forecast horizon (Clement, 1999; O'Brien, 1990; Jacob et al., 1999) and the number of firms and industries followed (Clement, 1999). Forecast performance is also known to improve with the individual analyst's prior forecast accuracy (Brown, 2001; Clement et al., 2007; Park \& Stice, 2000). Analyst firm-specific experience is another popular control in extant literature (Hong \& Kubik, 2003). For instance, Cowen (2006) uses firm specific experience to study forecast optimism differences among various types of analysts. Similarly, Barniv et al. (2005), Clement (1999), and Jacob et al. (1999) control with firm specific measures of experience while Clement (1999) adds a general experience variable. Clement et al. (2007), while controlling for general and firm specific experience, also includes industry experience and task-specific experience controls. Jacob et al. (1999) include

\footnotetext{
${ }^{9}$ Modifications of DD02 such as McNichols (2002) include growth in revenue to capture performance, and PPE (Francis et al., 2005) to expand the model to include depreciation. Typically total current accruals (TCA) is estimated as: $\mathrm{TCA}_{\mathrm{jt}}=\alpha+\beta 1 \mathrm{CFO}_{\mathrm{j}, \mathrm{t}-1}+\beta 2 \mathrm{CFO}_{\mathrm{jt}}+\beta 3 \mathrm{CFO}_{\mathrm{j}, \mathrm{t}+1}+\beta 4$ $\Delta \mathrm{REV}_{\mathrm{jt}}+\beta 5 \mathrm{PPE}_{\mathrm{jt}}+\mathrm{v}_{\mathrm{jt}}$. Dechow et al., (2010) state that because the model decomposes the standard deviation of the residual into firm-level "innate" estimation errors and "discretionary" estimation errors, managerial choices could be examined which is not the purpose of DD02.

${ }^{10}$ DD02 in their footnote 6 state that an alternative measure of accrual quality at the firm-year level is absolute value of the residual for that year.
} 
controls for what they refer to as "situational" differences among analysts. These are differences that result from the demands and environment of the particular brokerage house. To control for these differences Barniv et al. (2005) and Jacob et al. (1999) use variables for brokerage size, specialization, and two controls for employee turnover. Prior work also controls for the frequency of forecasts made by the analyst for a particular company and earnings number (Clement et al., 2007; Jacob et al., 1999) and for individual analyst specialization (Jacob et al., 1999). However some prominent studies find no evidence that analysts learn and improve with experience (Clement et al., 2007). Furthermore Cowen et al. (2006) find that experience is not significant to forecast over-estimates in the shorter run (for 0-90 days) but significantly increases over-estimates for horizons longer than 90 days. They interpret these findings to mean that the longer an analyst covers a company, the less objective they are about bad news relative to other analysts; likely because they either become confident in the management team or rely more on management's assessment. The control variable definitions are presented next, grouped according to the model in which they are utilized.

\section{RFE Control Variable Definitions}

Because prior research finds that work place factors (situational variables) are significant for explaining variation in earnings forecast accuracy (Barniv et al., 2005; Clement, 1999; Jacob et al., 1999), included are controls for horizon, analyst firm-specific experience, frequency of forecasts made by the analyst for a particular firm and period, analyst specialization, brokerage size, brokerage specialization, analyst turnover at the analyst's brokerage firm, and finally a control for whether a change in the analyst has occurred at a particular brokerage that follows a specific firm.

Prior research (Brown, 2001; Clement and Tse, 2003; Jacob et al., 1999) find that longer forecast horizons are associated with less accurate the forecasts. Following Jacob et al. (1999) the forecast horizon control (HORIZ) captures the number of days between the forecast issue date and the earnings announcement date. Barniv et al. (2005) and Jacob et al. (1999) include the analyst's firm-specific experience as a control in their forecast accuracy models. However several studies find that experience gained through feedback does not improve analyst performance (Clement et al., 2007; Jacob et al., 1999; Mikhail et al., 1997). The variable FIRMEXP is included to control for the analyst's experience specific to a given firm. Following Jacob et al. (1999), FIRMEXP is measured as the natural logarithm of the number of periods that the analyst has issued forecasts for a specific company prior to the current period.

Jacob et al. (1999) include and find significance for "situational" based differences in analyst performance. They find that the working environment and other structural differences among brokerage firms. Other prior research has also included these controls to examine accuracy as well (Barniv et al., 2005). These situational differences are 1) BSIZE which is broker size defined as the percentile ranking of the total number of analysts employed by the particular analyst's brokerage in the year of the forecast, relative to other brokerage houses. BIND represents the broker industry percentage defined as the percentage of an individual analyst's brokerage house analysts that follow a specific company's industry in the year that the forecast was issued. PIN is the proportion of new analysts entering from outside the brokerage to the total number of analysts who worked for the brokerage during the year of the forecast. Finally POUT is defined as the proportion of analysts who left the brokerage to the total number of analysts who worked for the brokerage both during the year of the forecast.

Other individual analyst characteristic controls used in prior work (Barniv et al., 2005; Clement, 1999; Jacob et al., 1999) are also included in the accuracy model. These include FREQ which captures the number of forecasts made by the individual analyst for a specific firm and period; COMP which is the number of firms followed by the analyst in the year in which the specific forecast is issued; SPEC that equals the percentage of the firms followed by the individual analyst that are in the same industry as is the firm being forecast; and CHANGE which controls for whether there has been a change in the analyst that follows a particular firm at that particular brokerage for the earnings period for which the forecast is made.

\section{Regulation Control}

In late 2000, the SEC put into place regulations designed to inhibit the practice of management favoring certain analysts by disclosing useful information to them while withholding it from others. Regulation Fair 
Disclosure (Reg FD) was intended to insure equal access to all analysts. Prior to Reg FD, analysts may have resisted issuing unfavorable recommendations to investors because it may have resulted in their loosing access to management (Barniv et al., 2009). Reg FD was intended to take this constraint away by disallowing selective disclosure. Any effect of Reg FD on earnings quality could be expected to occur after 2000. Subsequent to FD, two other noteworthy actions with regard to analysts were taken by the regulators. First, in response to concerns that there was a conflict of interest between analysts and the investment banking business of their respective brokerages, the regulators responded with NASD Rule 2711 (Research Analysts and Research Reports) to discourage such conflict. Second, in late 2002 a settlement by the SEC was announced stemming from events which involved analysts from several investment banks purposely issuing misleading advice to public investors in order to benefit institutional clients. The "Global Research Analyst Settlement" took effect in early 2003 and required reforms in the methods investment banks used to distribute investing information. If these regulations in fact had their intended affects (more consistent disclosure of information and a reduction of conflicts of interest) it is reasonable to assume that the analyst community would benefit with better information on which to base their forecasts. Therefore it is anticipated that the regulations would enhance analyst performance and result in more accurate earnings forecasts. To capture this effect a dummy variable (REG) is included that is set to 1 if the firm year is later than 2000, otherwise zero.

\section{Other Controls}

Year indicator variables (YEAR) are included to control for time series effects. Also included are industry indicator variables (IND) based on the I/B/E/S SIG industry code scheme. ${ }^{11}$

\section{AFEP Control Variable Definitions}

The dependent variables HORIZ, BSIZE, REG, FIRMEXP, IND, and YEAR are retained from the RFE tests above. Following Tan et al. (2011) market value of equity to book value of equity (MTB) of firm $j$ for year $t$ is included. Examining the impact of IFRS adoption, they find a positive effect of MTB on accuracy. Following Bae et al. (2008), several other controls (DIVERSITY, SIZE, GENEX, and NFIRM) described next are included for the tests of AFEP. DIVERSITY is the diversity of analysts' forecasts for firm $\mathrm{j}$ in year $\mathrm{t}$ computed as the ratio of the standard deviation of forecasts for firm $\mathrm{j}$ in year $\mathrm{t}$ to the product of the absolute value of the consensus forecast and the square root of the number of analysts following firm $\mathrm{j}$ in year $\mathrm{t}$. SIZE is a control variable representing the size of firm $\mathrm{j}$ measured as the natural $\log$ of total assets in period $\mathrm{t}$ for firm $\mathrm{j}$. No_of_Analysts is the number of analysts covering firm $j$ in year t. GENEX is analyst $i$ 's general experience computed as the number of years between analyst $\mathrm{j}$ 's first forecast in $\mathrm{I} / \mathrm{B} / \mathrm{E} / \mathrm{S}$ and their current forecast in year $\mathrm{t}$. NFIRM is the number of firms followed by the analyst in the year in which the forecast is issued.

\section{Models}

\section{Relative Forecast Error (RFE)}

The first set of tests uses RFE as the dependent variable and controls defined above. As discussed above, the model is tested with two different lagged measurements of earnings quality based on DD02. The first is DDSD, which is the standard deviation of the most recent five years of residuals produced by the DD02 for each firm $\mathrm{j}$ and year $\mathrm{t}$;

$\mathrm{RFE}=\alpha+\beta_{1} \mathrm{DDSD}_{\mathrm{tj}}+\beta_{2}$ REG $+\beta_{3} \mathrm{HORIZ}_{\mathrm{ijj}}+\beta_{4} \mathrm{FIRMEXP}_{\mathrm{itj}}+\beta_{5} \mathrm{FREQ}_{\mathrm{itj}}+\beta_{6} \mathrm{COMP}_{\mathrm{itj}}+\beta_{7} \mathrm{SPEC}_{\mathrm{itj}}+$ $\beta_{8}$ BSIZE $_{i \mathrm{ij}}+\beta_{90} \mathrm{BIND}_{\mathrm{itj}}+\beta_{10} \mathrm{PIN}_{\mathrm{itj}}+\beta_{11}$ POUT $_{\mathrm{itj}}+\beta_{12} \mathrm{CHANGE}_{\mathrm{itj}}+\beta_{13} \mathrm{IND}_{\mathrm{it}}+\beta_{14} \mathrm{YEAR}_{\mathrm{tj}}+\mathrm{e}$

Alternatively the model is tested using DDCR as the earnings quality measurement. DDCR represents the residuals produced by the DD02 model for each firm $\mathrm{j}$ for a single year;

\footnotetext{
${ }^{11}$ The industry segments included from the I/B/E/S SIG codes are Health Care (default), Non-durable goods, Service Industries, Durable Goods, Energy, Transportation, Technology, Basic Industries, Capital, and Other.
} 
$\mathrm{RFE}=\alpha+\beta_{1} \mathrm{DDCR}_{\mathrm{tj}}+\beta_{2} \mathrm{REG}+\beta_{3} \mathrm{HORIZ}_{\mathrm{ijj}}+\beta_{4} \mathrm{FIRMEXP}_{\mathrm{itj}}+\beta_{5} \mathrm{FREQ}_{\mathrm{itj}}+\beta_{6} \mathrm{COMP}_{\mathrm{itj}}+\beta_{7} \mathrm{SPEC}_{\mathrm{itj}}+$ $\beta_{8}$ BSIZE $_{\mathrm{itj}}+\beta_{90}$ BIND $_{\mathrm{itj}}+\beta_{10} \mathrm{PIN}_{\mathrm{itj}}+\beta_{11}$ POUT $_{\mathrm{itj}}+\beta_{12} \mathrm{CHANGE}_{\mathrm{itj}}+\beta_{13} \mathrm{IND}_{\mathrm{it}}+\beta_{14} \mathrm{YEAR}_{\mathrm{tj}}+\mathrm{e}$

where the individual analyst is given as $\mathrm{i}$, firm is designated by $\mathrm{j}, \mathrm{t}$ denotes the fiscal year at the time of the earnings announcement date. All other variables are as described above.

Absolute Forecast Error Scaled by Price (AFEP)

The second set of tests uses AFEP as the dependent variable. As with RFE, the tests are performed using both DDSD and DDCR as the earnings quality variable. The impact of DDSD and DDCR on AFEP is examined by estimating the following models;

$$
\begin{aligned}
& \text { AFEP }_{\mathrm{itj}}=\alpha+\beta_{1} \text { DDSD }_{\mathrm{tj}}+\beta_{2} \text { DIVERSITY }_{\mathrm{tj}}+\beta_{3} \text { SIZE }_{\mathrm{tj}}+\beta_{4} \text { MTB }_{\mathrm{tj}}+\text { NO_OF_ANALYSTS }_{\mathrm{tj}}+\beta_{6} \text { FIRMEX }_{\mathrm{itj}}+ \\
& \beta_{7} \text { GENEX }_{\mathrm{it}}+\beta_{8} \text { BSIZE }_{\mathrm{tj}}+\beta_{9} \text { NFIRM }_{\mathrm{it}}+\beta_{10} \mathrm{HORIZ}_{\mathrm{ijj}}+\beta_{11} \mathrm{IND}_{\mathrm{jt}}+\beta_{12} \text { YEAR }+\mathrm{e}
\end{aligned}
$$

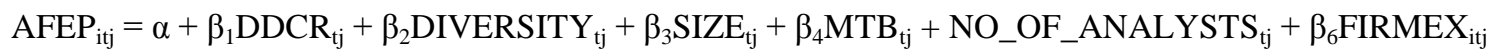

$$
\begin{aligned}
& +\beta_{7} \text { GENEX }_{\mathrm{it}}+\beta_{8} \text { BSIZE }_{\mathrm{tj}}+\beta_{9} \mathrm{NFIRM}_{\mathrm{it}}+\beta_{10} \mathrm{HORIZ}_{\mathrm{itj}}+\beta_{11} \mathrm{IND}_{\mathrm{jt}}+\beta_{12} \text { YEAR }+\mathrm{e}
\end{aligned}
$$

where AFEP is the absolute forecast accuracy scaled by the most recent stock price in the previous year. It is computed as the price scaled absolute difference between the last forecast issued by analyst $\mathrm{j}$ before the earnings announcement date and the actual earnings for firm $j$ in year $t$ multiplied by -100 . All other variables are as described above.

\section{Sample Data}

The models require the use of financial analyst performance data, and company level reported account balances from annual financial statements. All financial accounting reported balances are obtained from the Standard \& Poor's Research Insight Compustat 2010 North American Annual Industrial and Research files. The financial analyst data is obtained from the December, 2010 Institutional Brokers' Estimate System International (I/B/E/S) detail files. After combining the $\mathrm{I} / \mathrm{B} / \mathrm{E} / \mathrm{S}$ analyst data with the Compustat accounting data, omitting financial and utilities industries, eliminating all firm-year observations for which there was insufficient data, limiting the sample to contain only those observations of the most recent forecasts for each firm year observation (Barniv et al., 2005; Jacob et. al., 1999), and finally eliminating firm-year observations that have a following of less than two analysts, the final sample contains 604,316 firm-year-forecast observations, including 799 unique brokerages, 9,821 individual analysts, and 4,877 firms.

Table 1 provides descriptive statistics for the RFE tests. For RFE, the mean is 0.387 and the median is 0.523. The maximum value of 1 for RFE indicates that there is at least one analyst in the sample that had a zero error (a zero individual analyst error would produce an accuracy value of 1 using the RFE model above). DDSD is the lag of the standard deviation of a rolling time-series of residuals produced by estimation of the DD02 earnings quality model. The minimum value of zero indicates that for at least one firm in the sample residuals were unchanged for the five year estimation period. This suggests that earnings quality remained stable over the years that were measured. DDCR has a minimum value of zero and a mean of 0.038 . Because the variable is equal to the lag of the absolute value of the residuals produced from the DD02 regression, lower values indicate higher quality accruals. The minimum value of zero suggests that for at least one firm in the sample no accruals were made that did not convert to cash flows within the model's three year period. With regard to control variables, consistent with prior research (Barniv et al., 2005; Clement, 1999; Jacob et al., 1999) the analyst characteristic variables are adjusted to the mean values to make them consistent with the formulation of the dependent variable, however by convention, are reported at their values prior to subtracting the mean from each variable. HORIZ is measured as the number of days prior to the earnings announcement date that the most recent the forecast was made. The horizon for the forecasts in the sample ranges from zero to 365 days, with the mean being approximately 202 days. This indicates that the average most recent forecast in the sample is approximately 6.5 months prior to announcement. FIRMEXP is the experience of the analyst measured as the natural $\log$ of the number of periods the analyst provided forecasts for that firm. Because the natural $\log$ of 1 is zero, the minimum value of zero reported in the table suggests 
that the minimum number of years an analyst in the sample provided a forecast for the particular firm is one. The maximum value of 2.57 indicates that the maximum number of periods that an analyst provided forecasts for of a particular firm is approximately thirteen (the natural $\log$ of 13 is 2.56). REG is an indicator variable and appropriately has a minimum value of zero and a maximum value of one. The remaining control variables values are consistent with expectations.

\section{RESULTS}

\section{Descriptive Statistics for RFE Models}

Table 1 provides descriptive statistics for the RFE tests. For RFE, the mean is 0.387 and the median is 0.523. The maximum value of 1 for RFE indicates that there is at least one analyst in the sample that had a zero error (a zero individual analyst error would produce an accuracy value of 1 using the RFE model above). DDSD is the lag of the standard deviation of a rolling time-series of residuals produced by estimation of the DD02 earnings quality model. The minimum value of zero indicates that for at least one firm in the sample residuals were unchanged for the five year estimation period. This suggests that earnings quality remained stable over the years that were measured. DDCR has a minimum value of zero and a mean of 0.038 . Because the variable is equal to the lag of the absolute value of the residuals produced from the DD02 regression, lower values indicate higher quality accruals. The minimum value of zero suggests that for at least one firm in the sample no accruals were made that did not convert to cash flows within the model's three year period. With regard to control variables, consistent with prior research (Barniv et al., 2005; Clement, 1999; Jacob et al., 1999) the analyst characteristic variables are adjusted to the mean values to make them consistent with the formulation of the dependent variable, however by convention, are reported at their values prior to subtracting the mean from each variable. HORIZ is measured as the number of days prior to the earnings announcement date that the most recent the forecast was made. The horizon for the forecasts in the sample ranges from zero to 365 days, with the mean being approximately 202 days. This indicates that the average most recent forecast in the sample is approximately 6.5 months prior to announcement. FIRMEXP is the experience of the analyst measured as the natural $\log$ of the number of periods the analyst provided forecasts for that firm. Because the natural $\log$ of 1 is zero, the minimum value of zero reported in the table suggests that the minimum number of years an analyst in the sample provided a forecast for the particular firm is one. The maximum value of 2.57 indicates that the maximum number of periods that an analyst provided forecasts for of a particular firm is approximately thirteen (the natural $\log$ of 13 is 2.56). REG is an indicator variable and appropriately has a minimum value of zero and a maximum value of one. The remaining control variables values are consistent with expectations. 
Table 1: Descriptive Statistics for Tests of RFE

\begin{tabular}{|c|c|c|c|c|c|c|}
\hline Variable & $n$ & Mean & Std Dev & Median & Minimum & Maximum \\
\hline \multicolumn{7}{|l|}{ Dependent Variable } \\
\hline RFE & 604,273 & 0.387 & 0.572 & 0.523 & -62.65 & 1.00 \\
\hline \multicolumn{7}{|c|}{ Earnings Quality Variables } \\
\hline DDSD & 582,445 & 0.003 & 0.010 & 0 & 0 & 0.191 \\
\hline DDCR & 599,825 & 0.038 & 0.041 & 0.024 & 0 & 0.472 \\
\hline \multicolumn{7}{|l|}{ Control Variables } \\
\hline HORIZ & 604,316 & 202.0 & 103.0 & 196 & 0 & 365.0 \\
\hline FIRMEX & 604,316 & 0.951 & 0.708 & 1.10 & 0 & 2.57 \\
\hline FREQ & 604,316 & 7.449 & 3.404 & 7.00 & 1.00 & 12.0 \\
\hline COMP & 604,316 & 10.35 & 8.777 & 9.00 & 1.00 & 44.0 \\
\hline SPEC & 604,316 & 0.669 & 0.303 & 0.78 & 0.028 & 1.00 \\
\hline BSIZE & 604,316 & 87.70 & 18.00 & 96.00 & 15.00 & 99.0 \\
\hline BIND & 604,316 & 0.248 & 0.218 & 0.167 & 0.029 & 1.00 \\
\hline PIN & 604,316 & 0.093 & 0.124 & 0.059 & 0 & 0.733 \\
\hline POUT & 604,316 & 0.119 & 0.208 & 0.063 & 0 & 1.00 \\
\hline CHANGE & 604,316 & 0.101 & 0.302 & 0 & 0 & 1.00 \\
\hline REG & 604,316 & 0.484 & 0.50 & 0 & 0 & 1.00 \\
\hline
\end{tabular}

Individual analyst characteristics data is reported prior to subtracting the mean from each variable which results in a zero mean. $n$ indicates the number of observations for each of the variables. RFE is the quotient of the absolute forecast error for analyst $i$ in period $t$ for company $j$ divided by the mean absolute forecast error, then reduced by 1; (AFEitj/MAFEtj)-1 and then multiplied by -1 . HORIZ is the number of days between the forecast issue date and the earnings announcement date. CHANGE is a dummy variable that takes the value 1 if there has been a change in analyst following firm $\mathrm{j}$ for a particular brokerage in period t. FIRMEXP is the natural log of the number of years that analyst $i$ has issued forecasts for firm $\mathrm{j}$ prior to year t. COMP is the number of firms followed by the analyst in the year in which the forecast is issued. Spec is the percentage of the firms followed by analyst $i$ that are in the same $\mathrm{I} / \mathrm{B} / \mathrm{E} / \mathrm{S}$ industry classification as firm $\mathrm{j}$. FREQ is the number of forecasts made by analyst $\mathrm{i}$ for firm $\mathrm{j}$ for period t. BSIZE is a percentile ranking of the number of analysts working at the same brokerage as analyst $\mathrm{i}$, relative to other brokerages. BIND is the percentage of analysts that work at analyst i's brokerage that are following firm j's industry in the year $t$ in which the forecast was made. PIN is the proportion of new analyst assignments from outside the brokerage to the total number of analysts who worked for the brokerage during the year $\mathrm{t}$ in which the forecast was issued. POUT is the proportion of analysts that left the brokerage to the total number of analysts who worked for the brokerage during the year $t$ in which the forecast was issued. DDSD represents the lag of the standard deviation of the firm's level of earnings quality over the prior five consecutive years; DDCR represents the lag of the level of earnings quality for the firm in the year $t$. REG is a dummy variable that takes on a value of 1 if period $t$ is later than year 2000.

\section{Correlations for RFE Test Variables}

Table 2 reports the correlations among variables for the REF data. The table shows Pearson correlations above the diagonal and Spearman correlations below, each producing similar results. All correlations are significant at the $1 \%$ level unless otherwise indicated in the table. As expected from prior research, HORIZ is significantly correlated with relative forecast errors RFE. Recall that decreases in RFE indicate decreases in accuracy. Note that the negative association with RFE suggests that as forecast horizons increase, the relative forecast errors specification of accuracy decreases. As described above, higher values of DDSD and DDCR denote lower earnings quality. Therefore it is interesting to note that both test variables (DDSD and DDCR) are significantly correlated ( $\mathrm{p}$ $<.0001)$ with RFE respectively at -0.055 and -0.045 for Pearson and at -0.075 and -0.037 for Spearman, suggesting that low quality earnings are correlated with lower relative accuracy. For both Pearson and Spearman, all of the analyst characteristics variables are significantly associated with RFE at the $1 \%$ level. 
Table 2: RFE Test-Pearson/Spearman Correlations

\begin{tabular}{|c|c|c|c|c|c|c|c|c|c|c|c|c|c|c|}
\hline & RFE & DDSD & DDCR & Horiz & Firmex & Freq & Comp & Spec & Bsize & Bind & Pin & Pout & Change & Reg \\
\hline RFE & 1.000 & -0.055 & -0.045 & -0.362 & 0.021 & 0.038 & 0.006 & 0.032 & 0.030 & -0.013 & 0.010 & 0.004 & -0.082 & 0.067 \\
\hline DDSD & -0.075 & 1.000 & 0.234 & 0.054 & -0.048 & -0.141 & -0.020 & -0.079 & -0.033 & 0.008 & $0.003 \dagger$ & $0.0001 @$ & 0.060 & -0.062 \\
\hline DDCR & -0.037 & 0.093 & 1.000 & -0.003 & -0.113 & -0.133 & -0.099 & -0.030 & -0.039 & 0.055 & -0.005 & -0.001 & 0.055 & -0.098 \\
\hline Horiz & -0.437 & 0.098 & 0.0002@ & 1.000 & 0.115 & 0.107 & $0.001 @$ & -0.009 & 0.015 & -0.006 & -0.027 & 0.013 & 0.010 & 0.043 \\
\hline Firmex & 0.005 & -0.010 & -0.099 & 0.113 & 1.000 & 0.403 & 0.117 & 0.005 & 0.032 & -0.079 & -0.327 & 0.168 & -0.412 & -0.169 \\
\hline Freq & 0.028 & -0.176 & -0.117 & 0.101 & 0.406 & 1.000 & 0.154 & 0.159 & 0.112 & -0.038 & -0.041 & 0.014 & -0.380 & 0.197 \\
\hline Comp & 0.019 & -0.017 & -0.108 & 0.005 & 0.111 & 0.183 & 1.000 & 0.044 & 0.221 & -0.267 & 0.117 & 0.193 & -0.056 & -0.013 \\
\hline Spec & 0.040 & -0.128 & -0.010 & -0.009 & -0.021 & 0.146 & 0.069 & 1.000 & 0.169 & 0.117 & 0.046 & 0.023 & -0.026 & 0.115 \\
\hline Bsize & 0.042 & -0.045 & -0.066 & 0.016 & 0.036 & 0.121 & 0.423 & 0.163 & 1.000 & -0.575 & 0.136 & 0.183 & -0.031 & 0.089 \\
\hline Bind & -0.016 & -0.004 & 0.100 & 0.0006@ & -0.101 & -0.063 & -0.363 & 0.096 & -0.565 & 1.000 & -0.090 & -0.144 & 0.028 & 0.027 \\
\hline Pin & 0.038 & -0.035 & -0.037 & -0.007 & -0.266 & 0.023 & 0.302 & 0.101 & 0.425 & -0.258 & 1.000 & -0.067 & 0.181 & 0.109 \\
\hline Pout & 0.021 & -0.027 & -0.035 & 0.012 & 0.114 & 0.067 & 0.419 & 0.082 & 0.485 & -0.332 & 0.234 & 1.000 & -0.050 & -0.119 \\
\hline Change & -0.071 & 0.060 & 0.045 & 0.011 & -0.410 & -0.362 & -0.062 & -0.015 & -0.028 & 0.035 & 0.122 & -0.052 & 1.000 & -0.009 \\
\hline Reg & 0.083 & -0.067 & -0.085 & 0.048 & -0.160 & 0.200 & 0.015 & 0.122 & 0.123 & 0.037 & 0.250 & 0.0012@ & -0.009 & 1.000 \\
\hline
\end{tabular}

Pearson correlations are shown above the diagonal. Spearman correlations are shown below the diagonal. All correlations are significant at the $1 \%$ level $($ Prob $>|\mathrm{r}|$ under Ho: Rho $=0)$ unless otherwise indicated. @ indicates no significance, $\dagger$ indicates significance at the 5\% level, and \# indicates significance at the 10\% level. RFE is the quotient of the absolute forecast error for analyst i in period t for company j divided by the mean absolute forecast error, then reduced by 1; (AFEitj/MAFEtj)-1 and then multiplied by -1. DDSD represents the lag of the standard deviation of the firm's level of earnings quality over the prior five consecutive years, DDCR represents the lag of the level of earnings quality for the firm in the year t. HORIZ is the number of calendar days between the forecast issue date for company $\mathrm{j}$ and the earnings announcement. EXP is the natural log of the number of years that analyst $\mathrm{i}$ has issued forecasts for firm $\mathrm{j}$ prior to year t. COMP is the number of firms followed by the analyst in the year in which the forecast is issued. SPEC is the percentage of the firms followed by analyst $\mathrm{i}$ that are in the same I/B/E/S industry classification as firm $\mathrm{j}$. FREQ is the number of forecasts made by analyst $\mathrm{i}$ for firm $\mathrm{j}$ for period t. BSIZE is a percentile ranking of the number of analysts working at the same brokerage as analyst $\mathrm{i}$, relative to other brokerages. BIND is the percentage of analysts that work at analyst i's brokerage that are following firm j's industry in the year $t$ in which the forecast was made. PIN is the proportion of new analyst assignments from outside the brokerage to the total number of analysts who worked for the brokerage during the year $t$ in which the forecast was issued. POUT is the proportion of analysts that left the brokerage to the total number of analysts who worked for the brokerage during the year $t$ in which the forecast was issued. CHANGE is a dummy variable that takes the value 1 if there has been a change in analyst following firm $\mathrm{j}$ for a particular brokerage in period $\mathrm{t}$. REG is a dummy variable that equals 1 if period $\mathrm{t}$ is later than year 2000. 


\section{Results of RFE Tests}

Table 3 shows the results of OLS regression for the RFE tests. ${ }^{12}$ The expected coefficient sign is indicated next to each variable name. Recall that higher REF values indicate increased accuracy; therefore positive coefficients indicate increased accuracy on the dependent variable. Recall from the hypothesis development that earnings quality could affect financial analyst performance in opposing ways. Therefore, as indicated above, although the earnings quality variables (DDSD or DDCR) are expected to have an impact on RFE, no prediction is made as to the direction of that impact. Signs on the control variables are expected to be consistent with prior literature (Barniv et al., 2005; Jacob et al., 1999). Because regulations are expected to provide more reliable information to market participants, a positive sign is predicted on REG thus increasing accuracy. The results for DDSD are presented first. DDSD represents that standard deviation of residuals produced by estimating the DD02 model over the most recent five years. Therefore higher levels of DDSD indicate lower earnings quality. Thus the negative coefficient on DDSD (-1.4967) indicates that higher values of DDSD result in lower accuracy. The effect is significant at the 1 percent level $(\mathrm{p}<.0001)$, thus providing evidence to reject the null for $\mathrm{H} 1$ and indicating that decreased earnings quality results in lower forecast accuracy in the RFE tests. REG is positive (0.0986) and significant $(\mathrm{p}<.0001)$ indicating that analysts produce less relative forecast errors in the post regulation period. This result is consistent with prior literature (Barber et al., 2006; Barniv et al., 2009; Kadan et al., 2009). The coefficients on all controls are of their predicted direction except for PIN and POUT. The result for these controls seems to indicate that analysts that work in brokerages with high turnover are more accurate than those that work in other brokerage firms. One possible explanation for this result is that firms that engage in high levels of turnover activity may do so to maintain better performing analysts. The last column provides the results for the DDCR tests. Note that the coefficient on DDCR is negative $(-0.4433)$ and significant at the 1 percent level $(\mathrm{p}<.0001)$, providing further evidence to reject $\mathrm{H} 1$ and indicating that decreased earnings quality results in lower forecast accuracy. All DDCR control variables are consistent with the DDSD tests. Overall the results in Table 3 provide evidence to reject H1. These results reinforce the notion found in prior studies that better quality earnings reports do enhance the efforts of financial statement users (Barron \& Stuerke, 1998; Imhoff \& Lobo 1992; Mensah et al., 2004; Payne $\&$ Robb, 2000). This finding highlights the importance of high quality earnings to those that depend on financial statements for their predictive qualities.

\footnotetext{
${ }^{12}$ Heteroscedasticity-consistent standard errors and t-statistics are used to report the results of all tests of RFE and AFEP.
} 
Table 3: RFE Results for DDSD and DDCR

\begin{tabular}{|c|c|c|c|c|c|}
\hline \multicolumn{6}{|c|}{$\begin{array}{l}\text { RFE }=\alpha+\beta_{1} \text { Earnings Quality }{ }_{\mathrm{tj}}+\beta_{2} \text { REG }+\beta_{3} \text {HORIZ }_{\mathrm{itj}}+\beta_{4} \mathrm{EXP}_{\mathrm{itj}}+\beta_{5} \mathrm{FREQ}_{\mathrm{itj}}+\beta_{6} \mathrm{COMP}_{\mathrm{itj}}+\beta_{7} \text { SPEC }_{\mathrm{itj}}+\beta_{8} \text { SIZE }_{\mathrm{itj}}+\beta_{9} \mathrm{BIND}_{\mathrm{itj}} \\
\beta_{10} \mathrm{PIN}_{\mathrm{itj}}+\beta_{11} \text { POUT }_{\mathrm{itj}}+\beta_{12} \text { CHANGE }_{\mathrm{itj}}+\beta_{13} \mathrm{IND}_{\mathrm{it}}+\beta_{14} \text { YEAR }_{\mathrm{tj}}+\mathrm{e}\end{array}$} \\
\hline \multirow[b]{2}{*}{ Independent Variable } & \multirow[b]{2}{*}{ Predicted Sign } & \multicolumn{4}{|c|}{ Earnings Quality Variable } \\
\hline & & \multicolumn{2}{|c|}{ DDSD } & \multicolumn{2}{|c|}{ DDCR } \\
\hline Intercept & & 0.3926 & $* * *$ & 0.3982 & $* * *$ \\
\hline Earnings Quality Variable & $+/-$ & -1.4967 & $* * *$ & -0.4433 & $* * *$ \\
\hline REG & + & 0.0986 & $* * *$ & 0.0992 & $* * *$ \\
\hline HORIZ & - & -0.0021 & $* * *$ & -0.0021 & $* * *$ \\
\hline FIRMEX & + & 0.0422 & $* * *$ & 0.0438 & $* * *$ \\
\hline FREQ & + & 0.0022 & $* * *$ & 0.0038 & $* * *$ \\
\hline COMP & - & -0.0001 & $* *$ & -0.0003 & $* * *$ \\
\hline SPEC & $+/-$ & 0.0199 & $* * *$ & 0.0222 & $* * *$ \\
\hline BSIZE & + & 0.0007 & $* * *$ & 0.0007 & $* * *$ \\
\hline BIND & + & 0.0108 & $* *$ & 0.0098 & $* *$ \\
\hline PIN & - & 0.0328 & $* * *$ & 0.0379 & $* * *$ \\
\hline POUT & - & 0.0168 & $* * *$ & 0.0168 & $* * *$ \\
\hline CHANGE & $+/-$ & -0.0744 & $* * *$ & -0.081 & $* * *$ \\
\hline IND & & Included & & Included & \\
\hline YEAR & & Included & & Included & \\
\hline Adjusted $R^{2}$ & & $15.59 \%$ & & $15.32 \%$ & \\
\hline$E\left(n v u_{u}\right)$ & & 2988.42 & & 3014.43 & \\
\hline$F(p$ value $)$ & & $(<.0001)$ & & $(<.0001)$ & \\
\hline$n$ & & 582,434 & & 599,797 & \\
\hline
\end{tabular}

*,**, *** indicate statistical significance at the $10 \%, 5 \%$, and $1 \%$ levels, respectively. RFE is the quotient of the absolute forecast error for analyst $\mathrm{i}$ in period $\mathrm{t}$ for company $\mathrm{j}$ divided by the mean absolute forecast error, then reduced by 1 ; (AFEitj/MAFEtj)- 1 and then multiplied by -1 . DDSD represents the lag of the standard deviation of the firm's level of earnings quality over the prior five consecutive years, DDCR represents the lag of the level of earnings quality for the firm in the year t. REG is an indicator that takes on a value of 1 if period $t$ is later than year 2000 . HORIZ is the number of calendar days between the forecast issue date for company $j$ and the earnings announcement. EXP is the ln of the number of years that analyst $i$ has issued forecasts for firm $j$ prior to year t. FREQ is the number of forecasts made by analyst $i$ for firm $j$ for period t. COMP is the number of firms followed by the analyst in the year in which the forecast is issued. SPEC is the \% of the firms followed by analyst $i$ that are in the same $\mathrm{I} / \mathrm{B} / \mathrm{E} / \mathrm{S}$ industry classification as firm $\mathrm{j}$. BSIZE is a percentile ranking of the number of analysts working at the same brokerage as analyst $i$, relative to other brokerages. BIND is the \% of analysts that work at analyst i's brokerage that are following firm $j$ 's industry in the year $\mathrm{t}$ in which the forecast was made. PIN is the proportion of new analyst assignments from outside the brokerage to the total analysts who worked for the brokerage during the year $t$ in which the forecast was issued. POUT is the proportion of analysts that left the brokerage to the total number of analysts who worked for the brokerage during the year $t$ in which the forecast was issued. CHANGE is an indicator that takes the value 1 if there has been a change in analyst following firm $\mathrm{j}$ for a particular brokerage in period t. IND is a control using the $\mathrm{I} / \mathrm{B} / \mathrm{E} / \mathrm{S}$ industry classification. YEAR is a control representing the year in which firm j's earnings are reported.

\section{Descriptive Statistics for AFEP Models}

Table 4 provides the descriptive statistics for the AFEP model variables. Note that similar to prior literature (Bae et al., 2008) AFEP has a maximum value of zero and a minimum of -4.75 . The minimum value of DDSD is zero indicating that for at least one firm in the sample the residuals were unchanged for the five year estimation period. This indicates that earnings quality remained stable over the years that were measured. DDCR has a minimum value of zero and a mean of 0.0381. Because the variable is equal to residuals produced from the DD02 regression, lower values indicate higher quality accruals. The minimum DIVERSITY value is zero indicating no (or low) uncertainty. SIZE is the natural log of the firm's total assets. Because total assets are reported in millions, the mean value of 6.843 reported in the table indicates that the average value of firms' total assets in the sample is $\$ 937$ million. Also similar to prior literature (Tan et al., 2011) the No_of_Analysts mean value is 16.43. The mean value of NFIRM indicates that average number of companies that were followed by analysts in the sample is 10.35 , with the minimum of 1 and maximum of 44 . MTB values are percentages in the table; the minimum is negative (-74.58) and the maximum is 49.45. Firm specific experience of analysts (FIRMEX) ranges from zero to 2.565 years in the dataset and overall general forecasting experience (GENEX) ranges from zero to 18 years. All remaining variables in the table are consistent with Jacob et al. (1999). 
Table 4: Descriptive Statistics for Tests of AFEP

\begin{tabular}{|c|c|c|c|c|c|c|}
\hline Variable & $n$ & Mean & Std Dev & Median & Minimum & Maximum \\
\hline \multicolumn{7}{|l|}{ Dependent Variable } \\
\hline AFEP & 604,128 & -1.227 & 1.544 & -0.494 & -4.75 & 0 \\
\hline \multicolumn{7}{|c|}{ Earnings Quality Variables } \\
\hline DDSD & 582,385 & 0.003 & 0.010 & 0.00 & 0.00 & 0.19 \\
\hline DDCR & 599,672 & 0.0381 & 0.041 & 0.02 & 0.00 & 0.47 \\
\hline \multicolumn{7}{|l|}{ Control Variables } \\
\hline Reg & 604,128 & 0.484 & 0.500 & 0.00 & 0.00 & 1.00 \\
\hline Diversity & 604,128 & 0.012 & 0.082 & 0.00 & 0.00 & 0.64 \\
\hline Size & 604,128 & 6.843 & 1.843 & 6.76 & -0.83 & 12.69 \\
\hline MTB & 601,652 & 0.921 & 2.538 & 24.41 & -74.58 & 49.45 \\
\hline No_of_Analysts & 604,128 & 16.43 & 11.35 & 14.00 & 1.00 & 59.00 \\
\hline Firmex & 604,128 & 0.951 & 0.708 & 1.10 & 0.00 & 2.565 \\
\hline Genex & 604,128 & 4.671 & 3.945 & 4.00 & 0.00 & 18.00 \\
\hline Bsize & 604,128 & 87.71 & 17.98 & 96.00 & 15.00 & 99.00 \\
\hline Nfirm & 604,128 & 10.35 & 8.777 & 9.00 & 1.00 & 44.00 \\
\hline Horiz & 604,128 & 201.9 & 103.3 & 196.0 & 0.00 & 365.0 \\
\hline
\end{tabular}

AFEP is the absolute forecast accuracy scaled by the most recent stock price in the previous year. It is computed as the price scaled absolute difference between the last forecast issued by analyst $\mathrm{j}$ before the earnings announcement date and the actual earnings for firm $\mathrm{j}$ in year $\mathrm{t}$ multiplied by -100 . DDSD represents the lag of the standard deviation of the firm's level of earnings quality over the prior five consecutive years, DDCR represents the lag of the level of earnings quality for the firm in the year t. Reg is an indicator that takes on a value of 1 if period $t$ is later than year 2000. DIVERSITY is the diversity of analysts' forecasts for firm $\mathrm{j}$ in year t computed as the ratio of the standard deviation of forecasts for firm $\mathrm{j}$ in year $\mathrm{t}$ to the product between the absolute value of consensus forecast and the square root of the number of analysts following firm $\mathrm{j}$ in year $\mathrm{t}$. SIZE is a control variable representing the size of firm $\mathrm{j}$ measured as the natural log of total assets in period $\mathrm{t}$ for firm $\mathrm{j}$. MTB is the ratio of market value of equity to book value of equity for firm $\mathrm{j}$ for year t. No_of_Analysts is the number of analysts covering firm $\mathrm{j}$ in year t. FIRMEX is the ln of the number of years that analyst $i$ has issued forecasts for firm $j$ prior to year t. GENEX is analyst $i$ 's general experience computed as the number of years between analyst $\mathrm{j}$ 's first forecast in $\mathrm{I} / \mathrm{B} / \mathrm{E} / \mathrm{S}$ and their current forecast in year $\mathrm{t}$. BSIZE is a percentile ranking of the number of analysts working at the same brokerage as analyst i, relative to other brokerages. NFIRM is the number of firms followed by the analyst in the year in which the forecast is issued. HORIZ is the number of calendar days between the forecast issue date for company $\mathrm{j}$ and the earnings announcement.

\section{Correlations for AFEP Test Variables}

Table 5 gives the correlations for the AFEP model variables. All correlations are significant at the 1 percent level unless otherwise indicated in the table. Pearson correlations are shown above the diagonal and Spearman correlations are shown below. Note that for both Pearson and Spearman, AFEP is negatively and significantly associated with both DDSD and DDCR. This relationship indicates that as earnings quality declines, analyst accuracy decreases. This association is expected given the results of the RFE tests above. Also note that DIVERSITY, which is a measurement of uncertainty (Bae et al., 2008), is also negatively and significantly associated with AFEP for both Pearson and Spearman. This correlation indicates that greater uncertainty is associated with lower analyst forecast accuracy. Also for both Pearson and Spearman GENEX is positively and significantly associated with AFEP. However the result for FIRMEX is counterintuitive; it is negatively and significantly associated with AFEP for Spearman but not for Pearson. No_of_Analysts is positively and significantly associated with AFEP for both Pearson and Spearman indicating that a larger following is associated with higher forecast accuracy. 
Table 5 AFEP Test-Pearson/Spearman Correlations

\begin{tabular}{|c|c|c|c|c|c|c|c|c|c|c|c|c|c|}
\hline & AFEP & DDSD & DDCR & Reg & Diversity & Size & MTB & $\begin{array}{c}\text { No-of- } \\
\text { Analysts }\end{array}$ & Firmex & Genex & Bsize & Comp & Horiz \\
\hline AFEP & 1.000 & -0.118 & -0.123 & 0.018 & -0.157 & 0.175 & 0.074 & 0.201 & -0.002@ & 0.021 & 0.006 & -0.053 & -0.269 \\
\hline DDSD & -0.089 & 1.000 & 0.234 & -0.062 & 0.061 & -0.280 & -0.084 & -0.242 & -0.048 & 0.041 & -0.032 & -0.020 & 0.054 \\
\hline DDCR & -0.091 & 0.093 & 1.000 & -0.098 & 0.062 & -0.332 & -0.112 & -0.149 & -0.113 & -0.073 & -0.039 & -0.099 & $-0.003 \dagger$ \\
\hline Reg & $-0.003 \dagger$ & -0.067 & -0.085 & 1.000 & 0.006 & 0.164 & 0.067 & 0.061 & -0.170 & 0.396 & 0.089 & -0.013 & 0.043 \\
\hline Diversity & -0.143 & 0.059 & 0.068 & -0.002@ & 1.000 & -0.102 & -0.032 & -0.097 & -0.013 & -0.008 & -0.019 & -0.015 & 0.017 \\
\hline Size & 0.159 & -0.289 & -0.314 & 0.160 & -0.109 & 1.000 & 0.490 & 0.674 & 0.219 & 0.171 & 0.125 & 0.114 & $0.002 \#$ \\
\hline MTB & 0.068 & -0.239 & -0.248 & 0.122 & -0.071 & 0.781 & 1.000 & 0.430 & 0.077 & 0.051 & 0.011@ & -0.010 & -0.004 \\
\hline No_of_Analysts & 0.203 & -0.375 & -0.162 & 0.098 & -0.124 & 0.704 & 0.619 & 1.000 & 0.142 & 0.058 & 0.046 & 0.052 & 0.007 \\
\hline Firmex & -0.008 & -0.010 & -0.099 & -0.160 & -0.016 & 0.220 & 0.184 & 0.148 & 1.000 & 0.194 & 0.031 & 0.117 & 0.115 \\
\hline Genex & 0.018 & 0.091 & -0.053 & 0.350 & -0.011 & 0.161 & 0.107 & 0.076 & 0.235 & 1.000 & 0.073 & 0.129 & 0.063 \\
\hline Bsize & 0.000@ & -0.045 & -0.066 & 0.123 & -0.021 & 0.178 & 0.075 & 0.083 & 0.036 & 0.123 & 1.000 & 0.221 & 0.015 \\
\hline Comp & -0.067 & -0.017 & -0.108 & 0.015 & -0.015 & 0.124 & 0.050 & 0.077 & 0.111 & 0.168 & 0.423 & 1.000 & $0.001 @$ \\
\hline Horiz & -0.320 & 0.098 & 0.000@ & 0.048 & 0.017 & $0.000 @$ & 0.005 & 0.006 & 0.113 & 0.074 & 0.016 & 0.005 & 1.000 \\
\hline
\end{tabular}

Pearson correlations are shown above the diagonal. Spearman correlations are shown below the diagonal. All correlations are significant at the $1 \%$ level $($ Prob $>|r|$ under Ho: Rho $=0)$ unless otherwise indicated. @ indicates no significance, $\dagger$ indicates significance at the $5 \%$ level, and \# indicates significance at the $10 \%$ level. AFEP is the absolute forecast accuracy scaled by the most recent stock price in the previous year. It is computed as the price scaled absolute difference between the last forecast issued by analyst $\mathrm{j}$ before the earnings announcement date and the actual earnings for firm $\mathrm{j}$ in year multiplied by -100 . DDSD represents the lag of the standard deviation of the firm's level of earnings quality over the prior five consecutive years, DDCR represents the lag of the level of earnings quality for the firm in the year $t$. Reg is an indicator that takes on a value of 1 if period $t$ is later than year 2000. DIVERSITY is the diversity of analysts' forecasts for firm $j$ in year $t$ computed as the ratio of the standard deviation of forecasts for firm $j$ in year $t$ to the product between the absolute value of consensus forecast and the square root of the number of analysts following firm $j$ in year $t$. SIZE year t. No_of_Analysts is the number of analysts covering firm $\mathrm{j}$ in year $t$. FRMEX is the ln of the number of years that analyst $i$ has issued forecasts for firm $\mathrm{j}$ prior to year $\mathrm{t}$. GENEX is analyst $\mathrm{i}$ ' general experience computed as the number of years between analyst $\mathrm{j}$ 's first forecast in $\mathrm{I} / \mathrm{B} / \mathrm{E} / \mathrm{S}$ and their current forecast in year $\mathrm{t}$. BSIZE is a percentile ranking of the number of analysts working at the same brokerage as analyst $i$, relative to other brokerages. NFIRM is the number of firms followed by the analyst in the year in which the forecast is issued. HORIZ is the number of calendar days between the forecast issue date for company $\mathrm{j}$ and the earnings announcement. 


\section{Results of AFEP Tests}

Table 6 shows the results of OLS regression for the AFEP tests. Note that the expected coefficient sign is indicated next to each variable in the table. DDSD results are presented first. The coefficient on DDSD is negative (-7.942) and significant at the 1 percent level, thus providing evidence for rejecting $\mathrm{H} 2$ and indicating that lower earnings quality reduces forecast accuracy. The negative sign indicates that larger values of DDSD have a decreasing effect on AFEP. This result is consistent with the RFE tests above and provides further confirmation that low earnings quality diminishes the accuracy of financial analysts. The results for MTB and FIRMEX are not consistent with expectations. Although diminutive, the coefficient of MTB is negative (-0.0003) indicating that large market-to-book ratios reduce forecast accuracy in the sample. FIRMEX is negative and significant in the model suggesting that higher levels of firm specific experience reduce forecast accuracy. One possible explanation for this result is that as experienced analysts cultivate long-term associations with a company's management, they may not feel comfortable disputing management's predictions and thus issue optimistic forecasts (Cowen et al., 2006). GENEX is positive and significant indicating that analysts in the sample with more overall experience produce more accurate forecasts. Consistent with Bae et al. (2008) the coefficient on DIVERSITY is negative and significant. The coefficients on all remaining control variables result in their expected signs. The results for the tests of DDCR are presented next in the table and are consistent with the DDSD results. Note that DDCR is negative (-3.421) and significant at the 1 percent level. Recall that lower values of AFEP indicate reduced accuracy (greater absolute forecast errors). This result provides additional support for rejecting $\mathrm{H} 2$, and indicates that lower earnings quality is associated with greater absolute forecast errors. The coefficients on the remaining controls are consistent with the DDSD results. Overall Table 6 provides support to reject $\mathrm{H} 2$, and is consistent with the results of the RFE tests above. Specifically earnings quality, whether measured as DDSD or DDCR, has a significant impact on the accuracy of financial analysts' earnings forecasts. This result is robust to both the RFE and AFEP measurements of earnings quality. 
Table 6: AFEP Results for DDSD and DDCR

\begin{tabular}{|c|c|c|c|c|c|}
\hline \multicolumn{6}{|c|}{$\begin{array}{l}\text { AFEP }=\alpha+\beta_{1} \text { DDSD }_{\mathrm{tj}}+\beta_{2} \text { REG }+\beta_{3} \text { DIVERSITY } \\
+\beta_{9}+\beta_{4} \text { SIZE }_{\mathrm{tj}}+\beta_{5} \mathrm{MTB}_{\mathrm{tj}}+\beta_{6} \mathrm{No}_{-} \text {of_Anitj }+\beta_{10} \text { NFIRM }_{\mathrm{itj}}+\beta_{11} \text { HORIZitj }+\beta_{12} \mathrm{IND}_{\mathrm{it}}+\beta_{13} \text { YEAR }_{\mathrm{tj}}+\mathrm{e}\end{array}$} \\
\hline \multirow[b]{2}{*}{ Independent Variable } & \multirow[b]{2}{*}{ Predicted Sign } & \multicolumn{4}{|c|}{ Earnings Quality Variable } \\
\hline & & \multicolumn{2}{|c|}{ DDSD } & \multicolumn{2}{|c|}{ DDCR } \\
\hline Intercept & & -1.320 & $* * *$ & -1.168 & $* * *$ \\
\hline Earnings Quality Variable & $+/-$ & -7.942 & $* * *$ & -3.421 & $* * *$ \\
\hline REG & + & 0.160 & $* * *$ & 0.172 & $* * *$ \\
\hline DIVERSITY & $+/-$ & -2.277 & $* * *$ & -2.268 & $* * *$ \\
\hline SIZE & + & 0.112 & $* * *$ & 0.098 & $* * *$ \\
\hline MTB & + & -0.0003 & $* * *$ & -0.0003 & $* * *$ \\
\hline No_of_Analysts & + & 0.017 & $* * *$ & 0.019 & $* * *$ \\
\hline FIRMEX & + & -0.012 & $* * *$ & -0.020 & $* * *$ \\
\hline GENEX & + & 0.010 & $* * *$ & 0.0084 & $* * *$ \\
\hline BSIZE & + & 0.0006 & $* * *$ & 0.0007 & $* * *$ \\
\hline NFIRM & - & -0.006 & $* * *$ & -0.006 & $* * *$ \\
\hline HORIZ & - & -0.004 & $* * *$ & -0.004 & $* * *$ \\
\hline IND & & Included & & Included & \\
\hline YEAR & & Included & & Included & \\
\hline Adjusted $R^{2}$ & & $19.26 \%$ & & $19.78 \%$ & \\
\hline & & 3955.3 & & 4207.83 & \\
\hline$F$ (p value $)$ & & $(<.0001)$ & & $(<.0001)$ & \\
\hline$n$ & & 580,075 & & 597,249 & \\
\hline
\end{tabular}

* $* * * * * *$ indicate statistical significance at the $10 \%, 5 \%$, and $1 \%$ levels, respectively. AFEP is the absolute forecast accuracy scaled by the most recent stock price in the previous year. It is computed as the price scaled absolute difference between the last forecast issued by analyst $\mathrm{j}$ before the earnings announcement date and the actual earnings for firm $\mathrm{j}$ in year $\mathrm{t}$ multiplied by -100 . DDSD represents the lag of the standard deviation of the firm's level of earnings quality over the prior five consecutive years, DDCR represents the lag of the level of earnings quality for the firm in the year t. REG is an indicator that takes on a value of 1 if period t is later than year 2000. DIVERSITY is the diversity of analysts' forecasts for firm $\mathrm{j}$ in year $\mathrm{t}$ computed as the ratio of the standard deviation of forecasts for firm $\mathrm{j}$ in year $\mathrm{t}$ to the product between the absolute value of consensus forecast and the square root of the number of analysts following firm $\mathrm{j}$ in year t. SIZE is a control variable representing the size of firm $\mathrm{j}$ measured as the natural $\log$ of total assets in period $\mathrm{t}$ for firm $\mathrm{j}$. MTB is the ratio of market value of equity to book value of equity for firm $\mathrm{j}$ for year t. No_of_Analysts is the number of analysts covering firm $\mathrm{j}$ in year t. FIRMEX is the ln of the number of years that analyst $\mathrm{i}$ has issued forecasts for firm j prior to year t. GENEX is analyst i's general experience computed as the number of years between analyst $\mathrm{j}$ 's first forecast in $\mathrm{I} / \mathrm{B} / \mathrm{E} / \mathrm{S}$ and their current forecast in year t. BSIZE is a percentile ranking of the number of analysts working at the same brokerage as analyst $\mathrm{i}$, relative to other brokerages. NFIRM is the number of firms followed by the analyst in the year in which the forecast is issued. HORIZ is the number of calendar days between the forecast issue date for company $\mathrm{j}$ and the earnings announcement. IND is a control using the $\mathrm{I} / \mathrm{B} / \mathrm{E} / \mathrm{S}$ industry classification. YEAR is a control representing the year in which firm j's earnings are reported.

\section{SUMMARY \& CONCLUSION}

This study investigates whether there is an empirical association between the quality of reported earnings and financial analyst forecast accuracy. Because literature cited reveals that individual financial analysts bring different abilities to the forecasting task, it is anticipated that analysts' forecast performance relative to each other will be affected by variations in earnings quality. Research also shows that firm summary performance measures are more value relevant when they directly and quickly capture information about firms' cash flows. To examine the relationship of forecast accuracy with earnings quality, this study uses accuracy specifications of the individual analyst relative to other analysts (RFE), and relative to actual reported earnings (AFEP). The tests are performed using two specifications of earnings quality that track accruals to cash flows. The results indicate that accuracy diminishes when earnings quality is low. These results are consistent with extant literature that indicates that low quality earnings, and user uncertainty that it could cause, reduces analyst performance. Two caveats should be mentioned. First, the DD02 model is designed to isolate (as the residual term in the model) any changes in working capital that do not track to cash flows in a three year time period centered around the current period. The residual is then considered to be a measurement of low quality accruals. However, it is important to recognize that accruals that mature to cash flows over a slightly longer horizon would be considered of low quality when they may in fact enhance the usefulness of reported earnings. Second, recall that the DDSD variable represents the smoothness of earnings quality values over a several year period. As such, the earnings of a firm with several years of low quality reports that exhibit very minor deviation from year to year would be assessed as high quality for DDSD, although it is unlikely that low quality earnings would persist over the five year period used in this study. The results of this 
study indicate that the level of earnings quality has a significant impact on the accuracy of financial analysts; specifically that high quality earnings enhance forecast accuracy. Market participants will benefit from these results by gaining incremental knowledge of the determinants of financial analyst forecast accuracy and by gaining further insight of how management's accounting choices and estimates affect financial analysts' forecasting performance.

\section{AUTHOR INFORMATION}

Dr. David Salerno received his Ph.D. degree in Accounting from Kent State University-Kent. He is currently an assistant professor at the Kania School of Management at the University of Scranton, Scranton, PA. His research interests include earnings quality, analysts' forecasts, and executive compensation. E-mail: david.salerno@scranton.edu

\section{REFERENCES}

1. Agnes Cheng, C. S., Zishang Liu, C., \& Thomas, W. (2012). Abnormal accrual estimates and evidence of mispricing. Journal of Business Finance \& Accounting, 39(1/2), 1-34.

2. Ashbaugh, H., \& Pincus, M. (2001). Domestic accounting standards, international accounting standards, and the predictability of earnings. Journal of Accounting Research, 39(3), 417-434.

3. Bae, K., Stulz, R. M., \& Tan, H. (2008). Do local analysts know more? A cross-country study of the performance of local analysts and foreign analysts. Journal of Financial Economics, 88(3), 581-606.

4. Ball, R., \& Shivakumar, L. (2006). The role of accruals in asymmetrically timely gain and loss recognition. Journal of Accounting Research, 44(2), 207-242.

5. Barber, B. M., Lehavy, R., McNichols, M., \& Trueman, B. (2006). Buys, holds, and sells: The Distribution of investment banks' stock ratings and the implications for the profitability of analysts' recommendations. Journal of Accounting \& Economics, 41(1/2), 87-117.

6. Barker, R., \& Imam, S. (2008). Analysts' perceptions of earnings quality. Accounting \& Business Research, 38(4): 313-329.

7. Barniv, R., Myring, M. J., \& Thomas, W. B. (2005). The association between the legal and financial reporting environments and forecast performance of individual analysts. Contemporary Accounting Research, 22(4), 727-758.

8. Barniv, R., Hope, O., Myring, M. J., \& Thomas, W. B. (2009). Do analysts practice what they preach and should investors listen? Effects of recent regulations. Accounting Review, 84(4), 1015-1039.

9. Barron, O. E., \& Stuerke, P. S. (1998). Dispersion in analysts' earnings forecasts as a measure of uncertainty. Journal of Accounting, Auditing \& Finance, 13(3), 245-270.

10. Barton, J., Hansen, T., \& Pownall, G. (2010). Which performance measures do investors around the world value the most and why? Accounting Review, 85(3), 753-789.

11. Bartov, E., Givoly, D., \& Hayn, C. (2002). The rewards to meeting or beating earnings expectations. Journal of Accounting \& Economics, 33(2), 173-204.

12. Bauman, M., \& Shaw, K. (2006). Stock option compensation and the likelihood of meeting analysts' quarterly earnings targets. Review of Quantitative Finance \& Accounting, 26(3), 301-319.

13. Bhattacharya, U., Daouk, H., \& Welker, M. (2003). The world price of earnings opacity. Accounting Review, 78(3), 641-678.

14. Boulton, T. J., Smart, S. B., \& Zutter, C. J. (2011). Earnings quality and international IPO underpricing. Accounting Review, 86(2), 483-505.

15. Brown, L. D. (2001). A temporal analysis of earnings surprises: Profits versus losses. Journal of Accounting Research, 39(2), 221-241.

16. Bryan, D. M., \& Tiras, S. L. (2007). The influence of forecast dispersion on the incremental explanatory power of earnings, book value, and analyst forecasts on market prices. Accounting Review, 82(3), 651-677.

17. Burgstahler, D., \& Dichev, I. (1997). Earnings management to avoid earnings decreases and losses. Journal of Accounting \& Economics, 24(1), 99.

18. Burgstahler, D. C., \& Eames, M. J. (2003). Earnings management to avoid losses and earnings decrease: Are analysts fooled? Contemporary Accounting Research, 20(2), 253-294.

19. Clement, M. B. (1999). Analyst forecast accuracy: Do ability, resources, and portfolio complexity matter? Journal of Accounting \& Economics, 27(3), 285-303. 
20. Clement, M. B., \& Tse, S. V. (2003). Do investors respond to analysts' forecast revisions as if forecast accuracy is all that matters? Accounting Review, 78(1), 227.

21. Clement, M. B., Koonce, L., \& Lopez, T. J. (2007). The roles of task-specific forecasting experience and innate ability in understanding analyst forecasting performance. Journal of Accounting \& Economics, 44(3), 378-398.

22. Core, J. E., Guay, W. R., \& Verrecchia, R. E. (2003). Price versus non-price performance measures in optimal ceo compensation contracts. Accounting Review, 78(4), 957-981.

23. Cowen, A., Groysberg, B., \& Healy, P. (2006). Which Types of Analyst Firms are More Optimistic? Journal of Accounting \& Economics, 41(1/2), 119-146.

24. Dechow, P. M., \& Dichev, I. D. (2002). The quality of accruals and earnings: The role of accrual estimation errors. Accounting Review, 77(4), 35.

25. Dechow, P., Ge, W., \& Schrand, C. (2010). Understanding earnings quality: A review of the proxies, their determinants and their consequences. Journal of Accounting \& Economics, 50(2/3), 344-401.

26. Dowdell Jr., T. D. (2010). Analyst forecasts and company life-cycle stages, an exploratory analysis. Journal of Theoretical Accounting Research, 5(2), 37-58.

27. Eames, M. J., \& Glover, S. M. (2003). Earnings predictability and the direction of analysts' earnings forecast errors. Accounting Review, 78(3), 707-724.

28. Feng, C., Ole-Kristian, H., Qingyuan, L., \& Xin, W. (2011). Financial reporting quality and investment efficiency of private firms in emerging markets. Accounting Review, 86(4), 1255-1288.

29. Francis, J., LaFond, R., Olsson, P. M., \& Schipper, K. (2004). Costs of equity and earnings attributes. Accounting Review, 79(4), 967-1010.

30. Francis, J., LaFond, R., Olsson, P., \& Schipper, K. (2005). The market pricing of accruals quality. Journal of Accounting \& Economics, 39(2), 295-327.

31. Gaio, C., \& Raposo, C. (2011). Earnings quality and firm valuation: International evidence. Accounting \& Finance, 51(2), 467-499.

32. García-Teruel, P. J., Martínez-Solano, P., \& Sánchez-Ballesta, J. (2009). Accruals quality and corporate cash holdings. Accounting \& Finance, 49(1), 95-115.

33. Graham, J. R., Harvey, C. R., \& Rajgopal, S. (2005). The economic implications of corporate financial reporting. Journal of Accounting \& Economics, 40(1-3), 3-73.

34. Graham, J. R., Harvey, C. R., \& Rajgopal, S. (2006). Value destruction and financial reporting decisions. Financial Analysts Journal, 62(6), 27-39.

35. Guttman, I., Kadan, O., \& Kandel, E. (2006). A rational expectations theory of kinks in financial reporting. Accounting Review, 81(4), 811-848.

36. Hayn, C. (1995). The information content of losses. Journal of Accounting \& Economics, 20(2), $125-153$.

37. Helbok, G., \& Walker, M. (2004). On the nature and rationality of analysts' forecasts under earnings conservatism. British Accounting Review, 36(1), 45.

38. Hong, H., \& Kubik, J. D. (2003). Analyzing the analysts: Career concerns and biased earnings forecasts. Journal of Finance, 58(1), 313-351.

39. Imhoff Jr., E. A., \& Lobo, G. J. (1992). The effect of ex-ante earnings uncertainty on earnings response coefficients. Accounting Review, 67(2), 427-439.

40. Jacob, J., Lys, T. Z., \& Neale, M. A. (1999). Expertise in forecasting performance of security analysts. Journal of Accounting \& Economics, 28(1), 51-82.

41. Jacob, J., \& Jorgensen, B. N. (2007). Earnings management and accounting income aggregation. Journal of Accounting \& Economics, 43(2/3), 369-390.

42. Kadan, O., Madureira, L., Wang, R., \& Zach, T. (2009). Conflicts of interest and stock recommendations: The effects of the global settlement and related regulations. Review of Financial Studies, 22(10), 41894217.

43. Kerstein, J., \& Rai, A. (2007). Intra-year shifts in the earnings distribution and their implications for earnings management. Journal of Accounting \& Economics, 44(3), 399-419.

44. Myungsun, K., \& Prather-Kinsey, J. (2010). An additional source of financial analysts' earnings forecast errors: Imperfect adjustments for cost behavior. Journal of Accounting, Auditing \& Finance, 25(1), $27-51$.

45. La Porta, R., Lopez-de-Silanes, F., Shleifer, A., \& Vishny, R. W. (1998). Law and finance. Journal of Political Economy, 106(6), 1113. 
46. Libby, R., Hunton, J. E., Tan, H., \& Seybert, N. (2008). Relationship incentives and the optimistic/pessimistic pattern in analysts' forecasts. Journal of Accounting Research, 46(1), 173-198.

47. Lobo, G. J., Song, M., \& Stanford, M. (2012). Accruals quality and analyst coverage. Journal of Banking \& Finance, 36(2), 497-508.

48. Lopez, T. J., \& Rees, L. (2002). The effect of beating and missing analysts' forecasts in the information content of unexpected earnings. Journal of Accounting, Auditing \& Finance, 17(2), 155-184.

49. Matsumoto, D. A. (2002). Management's incentives to avoid negative earnings surprises. Accounting Review, 77(3), 483-514.

50. McNichols, M. F. (2002). Discussion of the quality of accruals and earnings: The role of accrual estimation errors. Accounting Review, 77(4), 61.

51. Mensah, Y. M., Xiaofei, S., \& Ho, S. M. (2004). The effect of conservation on analysts' annual earnings forecast accuracy and dispersion. Journal of Accounting, Auditing \& Finance, 19(2), 159-183.

52. Mikhail, M. B., Walther, B. R., \& Willis, R. H. (1997). Do security analysts improve their performance with experience? Journal of Accounting Research, 35(3), 131-157.

53. Mohanram, P. S., \& Sunder, S. V. (2006). How has regulation fd affected the operations of financial analysts? Contemporary Accounting Research, 23(2), 491-525.

54. Murphy, K. (1999). Executive compensation in handbook of labor economics. Amsterdam: North-Holland.

55. O'Brien, P. C., \& Bhushan, R. (1990). Analyst following and institutional ownership. Journal of Accounting Research, 28(3), 55-82.

56. Park, C. W., \& Stice, E. K. (2000). Analyst forecasting ability and the stock price reaction to forecast revisions. Review of Accounting Studies, 5(3), 259-272.

57. Payne, J. L., \& Robb, S. G. (2000). Earnings management: The effect of ex ante earnings expectations. Journal of Accounting, Auditing \& Finance, 15(4), 371-392.

58. Penman, S. H., \& Xiao-Jun, Z. (2002). Accounting Conservatism, the quality of earnings, and stock returns. Accounting Review, 77(2), 237-264.

59. Raedy, J., Shane, P., \& Yanhua, Y. (2006). Horizon-dependent underreaction in financial analysts' earnings forecasts. Contemporary Accounting Research, 23(1), 291-322.

60. Roychowdhury, S. (2006). Earnings management through real activities manipulation. Journal of Accounting \& Economics, 42(3), 335-370.

61. Tan, H., Wang, S., \& Welker, M. (2011). Analyst following and forecast accuracy after mandated IFRS adoptions. Journal of Accounting Research, 49(5), 1307-1357. 
NOTES 